\title{
Health Related Quality of Life in Pregnant Women with Diabetes or Mild Hyperglycemia
}

Noeli A. Q. Marquesim¹, Silvana A. M. Lima2 ${ }^{\text {, Roberto A. A. Costa }}{ }^{3}$, Meline R. K. Rodrigues ${ }^{1}$, Guilherme A. R. Ferraz ${ }^{1}$, Ana C. Molina ${ }^{4}$, Bianca F. N. Cassetari ${ }^{1}$, Marilza V. C. Rudge ${ }^{1,3}$, Iracema M. P. Calderon ${ }^{1,3}$

\section{Abstract}

Background: Diabetes mellitus (DM) is a public health concern spread worldwide. Maternal diabetes in pregnancy increases risk of adverse perinatal and maternal outcomes; therefore; affecting the women's quality of life (QOL).

Objective: To evaluate quality of life in pregnant women with diabetes mellitus, gestational diabetes or mild gestational hyperglycemia.

Study Design: This is a prospective and longitudinal study. The sample comprised 105 pregnant women, i.e. 66 Hyperglycemic (HG) and 39 Normoglycemic (NG). The validated Whoqol-Bref/Quality of Life Assessment questionnaire was applied at the first prenatal appointment or at time of disease diagnosis; and re-applied at delivery admission or at 36-37 weeks' gestation.

Results: Most pregnant women considered good QOL at early pregnancy, but not at late pregnancy. In general, they were satisfied with their quality of life. NG pregnant women were more satisfied than their HG counterparts. At the onset of the gestational period the HG group obtained lower scores in the physical domain than the NG group. At the end of the gestational period, the scores on physical, psychological and environmental domains were significant lower in pregnant women with diabetes or hyperglycemia.

Conclusion: The study demonstrated that pregnant women with diabetes or hyperglycemia were compromised in certain aspects of quality of life.
1 Postgraduate education program in Gynecology, Obstetrics and Mastology, Botucatu Medical School, São Paulo State University, Botucatu, SP, Brazil.

2 Department of Nursing, , Botucatu Medical School, São Paulo State University, Botucatu, SP, Brazil.

3 Department of Gynecology and Obstetrics, Botucatu Medical School, São Paulo State University, Botucatu, SP, Brazil.

4 Nurse, Municipal Authority of Botucatu, São Paulo, Brazil.

\section{Contact information:}

\section{Guilherme Augusto Rago Ferraz.}

Address: Av. Prof. Montenegro, Rubião Junior District s/n.POSTCODE: 18618970. Botucatu, SP, Brazil.

Tel: (55) 14 3880-1400

”guilhermerago@yahoo.com.br
Keywords
Pregnancy; Diabetes Mellitus, Hyperglycemia; Life Quality; Outpatient Treatment; Hospital. 


\section{Introduction}

Diabetes mellitus (DM) is a public health concern in all of social environments. Affecting the quality of life (QOL); consequently, imposing a high burden on healthcare system [1]. The chronic hyperglycemia of diabetes causes disturbances in carbohydrate, fat and protein metabolism of which, in turn, impairs insulin secretion and/or action; thereby leading to dysfunction and failure of several organs, especially the eyes, kidneys, heart and blood vessels [2, 3]. Pregnancy in type 1 and type 2 DM increases morbidity, miscarriages and malformations at an early stage; gestational diabetes (GDM) affects late pregnancy by causing hypoglycemia, hypocalcemia, polycythemia, macrosomia, neonatal hyperbilirubinemia, and any diabetes type increase the risk of perinatal death [4-6]. Since last decade, the maternal hyperglycemia cases were not diagnosed as GDM, but as mild gestational hyperglycemia $(\mathrm{MHG})$; therefore, experts in high risk pregnancy recommend for both cases the control of maternal blood glucose [4,7-10]. QOL is defined as the individual's life perception in the context of culture and value system in relation to their aims, concerns and standards. Although, the assessment of QOL seems to be subjective, as each person has her own personal experience; QOL enables to establish new parameters to support the therapeutic approach in healthcare settings [11-14]. Despite the importance of individual and collective for health promotion, QOL assessment is uncommon in medical practice $[15,16]$. The World Health Organization (WHO) has developed a questionnaire for measuring QOL, i.e. the "World Health Organization Quality of Life" (WHOQOL), which is a 26 item-instrument consisting of four domains: physical health (7 items); psychological health (6 items); social relationships (3 items); and environment health (8 items). The WHOQOL-BREF is an abridged version; validated in Brazilian Portuguese; and being more suitable for evaluating populations or controlled clinical trials [14-17].
Regardless of pregnancy status, DM has been associated to loss on QOL $[1,18]$. Additionally, raising awareness is essential for pregnant women with pre-existing diabetes (i.e. MHG or GDM), as early diagnosis and starting short or long interventions are decisive to avoid adverse outcomes; to reduce costs of caring; therefore, improving QOL. Yet there is surprisingly little literature on this issue; thus the current study assessed QOL in pregnant women with prepregnancy DM, GDM and MHG, by applying the WHOQOL-BREF [11-14] at early and late pregnancy to compare the outcomes with those of non-diabetic pregnant women.

\section{Methods}

\section{Study design and location}

A longitudinal and comparative study was conducted at the Specialized Diabetes and Pregnancy Service of Botucatu Medical School - UNESP.

\section{Subjects}

All the pregnant women treated with the aforementioned services were sampled by convenience from September 2010 to December 2011. Therefore, women with prepregnancy DM, GDM or MHG were allocated to a hyperglycemia group (HG group/n=66), and their diagnosis was defined by a glucose tolerance test (GTT $100 \mathrm{~g} / 75 \mathrm{~g}$ ); and by a glycemic status $[3,4,8]$. Women with a normal glycemic status or women who exhibited risk factors, but were negative in the diagnostic test for diabetes, were allocated to a control group (NG group/n=39).

According to the institutional protocol, all pregnant women with MHG and GDM received a selective diet, which was constantly checked on outpatient treatment. Therefore, all women with gestational diabetes; insulin dependent associated with an special diet; and for controlling hyperglycemia; the treatment was followed-up within 24hs of admission, every fortnight until 28 weeks of pregnancy; 
or weekly within 24hs admission, after 28 weeks pregnancy until delivery.

\section{Evaluation Time}

Patients were assessed at early (T1) and late (T2) pregnancy:

- T1: first prenatal checkup for women with type 1 and 2 diabetes; or diagnosis time for GDM, MHG and NG.

- T2: at admission for delivery; or at 36-37 weeks' gestation.

\section{Assessment tools}

The validated and Portuguese version of the WHOQOL-BREF questionnaire [11-14] was applied on all participants in both evaluations time by the researcher in charge.

The WHOQOL-BREF, an abridged version of the World Health Organization Quality of Life (WHOQOL - 100) questionnaire, comprises 26 questions. Two questions (q1 and q2) are general questions, and the remaining 24 are divided into four domains: physical, psychological, social relationships and environmental. The physical domain is represented by questions 3, 4, 10, 15, 16, 17 and 18; the psychological by questions $5,6,7,11,19$ and 26; the social by questions 20,21 , and 22; and the environmental by questions 8, 9, 12, 13, 14, 23, 24 and 25. Each question is scored on a 1-5 scale; thus, higher scores indicate better QOL. The scores obtained were multiplied by four and converted domain scores to a 0-100 scale.

\section{Statistical Analysis}

Proportions were compared by Chi square or Fisher's exact test. Mean values were analyzed by ANOVA; followed by Tukey test for multiple comparisons. The significance threshold was 95\% $(P<0.05)$.

\section{Ethical aspects}

The Human Research Ethics Committee of Botucatu Medical School (UNESP) approved the current research under protocol \# 274/08. Therefore, all participants in this study have signed an Informed Consent.

\section{Results}

Table 1 shows the profile of the interviewed mothers. In the HG and NG groups, most women were in a stable relationship; had from 4 to 11 years of formal education; and worked outside from home. Mean age was different between the groups; thus a grea-

Table 1. Evolution on the assessment of QOL in hyperglycemic (HG) and normoglycemic (NG) pregnant women.

\begin{tabular}{|c|c|c|c|c|c|}
\hline & \multicolumn{2}{|c|}{ HG $(N=66)$} & \multicolumn{2}{|c|}{ NG $(\mathbf{N}=39)$} & \multirow{2}{*}{$p^{*}$} \\
\hline & $n$ & $\%$ & $n$ & $\%$ & \\
\hline \multicolumn{6}{|l|}{ Age (in years) } \\
\hline$<25$ years & 12 & 18.2 & 11 & 28.2 & \multirow{2}{*}{0.0043} \\
\hline$\geq 25$ years & 54 & 81.8 & 28 & 71.8 & \\
\hline \multicolumn{6}{|l|}{ Marital status } \\
\hline Single & 3 & 4.5 & 4 & 10.2 & \multirow{4}{*}{0.2264} \\
\hline Married & 37 & 56.1 & 21 & 53.9 & \\
\hline Living as married & 25 & 37.9 & 12 & 30.7 & \\
\hline Divorced & 1 & 1.5 & 2 & 5.2 & \\
\hline \multicolumn{6}{|l|}{ Education (in years) } \\
\hline 1 to 3 & 9 & 13.6 & 7 & 17.9 & \multirow{4}{*}{0.4860} \\
\hline 4 to 7 & 27 & 40.9 & 13 & 33.3 & \\
\hline 8 to 11 & 25 & 37.9 & 18 & 46.2 & \\
\hline$\geq 12$ & 5 & 7.6 & 1 & 2.6 & \\
\hline \multicolumn{6}{|c|}{ Work outside the home } \\
\hline No & 24 & 36.4 & 15 & 38.5 & \multirow{2}{*}{0.7696} \\
\hline Yes & 42 & 63.6 & 24 & 61.5 & \\
\hline \multicolumn{6}{|l|}{ Insulin } \\
\hline Yes & 50 & 75.8 & - & - & \multirow[b]{2}{*}{-} \\
\hline No & 16 & 24.2 & 39 & 100.0 & \\
\hline \multicolumn{6}{|c|}{ Type of hyperglycemia \# } \\
\hline DM1, DM2, GDM & 40 & 60.6 & - & - & \multirow{2}{*}{-} \\
\hline HGL & 26 & 39.4 & - & - & \\
\hline $\begin{array}{r}\text { *: Chi-squa } \\
\text { type } 1 \text { (DM1) a } \\
\text { gestational }\end{array}$ & $\begin{array}{l}\text { Fishe } \\
\text { pe } 2( \\
\text { tes } m\end{array}$ & $\begin{array}{l}\text { s exact } \\
\text { M2) di } \\
\text { Ilitus; I }\end{array}$ & $\begin{array}{l}\text { test, } \\
\text { abetes } \\
\text { MHG: }\end{array}$ & $\begin{array}{l}\text { : prepre } \\
\text { mellitus } \\
\text { nild ges } \\
\text { hyperg }\end{array}$ & $\begin{array}{l}\text { egnancy } \\
\text { s; GDM: } \\
\text { stational } \\
\text { glycemia }\end{array}$ \\
\hline
\end{tabular}


Table 2. Outcomes of the WHOQOL BREF instrument with regards to the quality of life and health status in hyperglycemic $(\mathrm{HG})$ and normoglycemic (NG) pregnant women.

\begin{tabular}{|c|c|c|c|c|c|c|c|c|c|c|}
\hline & \multicolumn{4}{|c|}{ HG $(\mathrm{N}=66)$} & \multicolumn{4}{|c|}{ NG $(\mathrm{N}=39)$} & \multicolumn{2}{|c|}{ P-value* } \\
\hline & \multicolumn{2}{|c|}{ M1 } & \multicolumn{2}{|c|}{ M2 } & \multicolumn{2}{|c|}{ M1 } & \multicolumn{2}{|c|}{ M2 } & \multirow{2}{*}{$p^{1}$} & \multirow{2}{*}{$p^{2}$} \\
\hline & $n$ & $\%$ & $\mathrm{n}$ & $\%$ & $n$ & $\%$ & $n$ & $\%$ & & \\
\hline \multicolumn{11}{|l|}{ Quality of life } \\
\hline Poor & 5 & 7.6 & 36 & 54.5 & 3 & 7.7 & 12 & 30.8 & \multirow{4}{*}{0.947} & \multirow{4}{*}{0.055} \\
\hline Neither poor nor good & 14 & 21.2 & 30 & 45.5 & 9 & 23.1 & 27 & 69.2 & & \\
\hline Good & 47 & 71.2 & 0 & 0.0 & 27 & 69.2 & 0 & 0.0 & & \\
\hline$p$-value* & \multicolumn{2}{|c|}{$p^{3}$} & \multicolumn{2}{|c|}{0.008} & \multicolumn{2}{|c|}{$p^{4}$} & \multicolumn{2}{|c|}{0.999} & & \\
\hline \multicolumn{11}{|l|}{ Health condition } \\
\hline Dissatisfied & 7 & 10.7 & 21 & 31.8 & 4 & 10.3 & 4 & 10.3 & \multirow{4}{*}{0.026} & \multirow{4}{*}{0.007} \\
\hline Neither satisfied nor dissatisfied & 22 & 33.3 & 25 & 37.9 & 4 & 10.3 & 4 & 10.3 & & \\
\hline Satisfied & 37 & 56.0 & 20 & 30.3 & 31 & 79.4 & 31 & 79.4 & & \\
\hline$p$-value* & \multicolumn{2}{|c|}{$p^{3}$} & \multicolumn{2}{|c|}{0.003} & \multicolumn{2}{|c|}{$p^{4}$} & \multicolumn{2}{|c|}{0.999} & & \\
\hline
\end{tabular}

ter proportion of women in the HG group were 25 years old or older. With regards to the DM (60.6\%) and MHG (39.4\%) women, 75.8\% used insulin in order to control blood glucose levels. According to the WHOQOL-BREF and regardless of the glycemic status, most women reported good QOL in early pregnancy (T1), but none considered it good at late pregnancy (T2). In the HG group, $54.5 \%$ of the women evaluated QOL as poor, and in the NG group $69.2 \%$ considered it neither poor nor good $(\mathrm{P}<0.05$; Table 2).

In T1, most women were satisfied with their health status, which was more frequent in NG than HG women (79.4 vs. $56.0 \%, p=0.026$ ). In $\mathrm{T} 2$, the proportion of women satisfied with their health decreased in the HG group (56.0\% to $30.3 \%$, p = 0.003 ) but not in NG ( $p=0.999)$.

Table 3 and Figure 1 show WHOQOL -BREF outcomes. In T1, HG women exhibited lower scores in the physical domain than NG women ( $p=$ 0.002). In T2, the scores in physical, psychological and environmental domains were significantly lower in pregnant women with $\mathrm{DM}$ or $\mathrm{MHG}$, but their scores were higher than those of the NG in the field of social relationships (73.3 vs. 61.1, $p=0.001$ ).
Table 3. WHOQOL BREF outcomes in relation to the physical; psychological; social; and environment in hyperglycemic (HG) and normoglycemic (NG) pregnant women.

\begin{tabular}{|c|c|c|c|c|c|c|}
\hline \multirow{3}{*}{ Domains } & \multicolumn{4}{|c|}{ HG $(N=66)$} & \multicolumn{2}{|c|}{ P-value* } \\
\hline & M1 & M2 & M1 & M2 & \multirow{2}{*}{$p^{1}$} & \multirow{2}{*}{$p^{2}$} \\
\hline & m (dp) & $m(d p)$ & m (dp) & $m(d p)$ & & \\
\hline Physical & $\begin{array}{l}61.9 \\
(9.6)\end{array}$ & $\begin{array}{l}52.5 \\
(8.2)\end{array}$ & $\begin{array}{l}65.6 \\
(7.4)\end{array}$ & $\begin{array}{l}65.6 \\
(7.4)\end{array}$ & \multirow[t]{2}{*}{0.002} & \multirow[t]{2}{*}{0.001} \\
\hline$p$-value* & $p^{3}$ & 0.001 & $p^{4}$ & 0.08 & & \\
\hline Psychological & $\begin{array}{l}68.0 \\
(7.7)\end{array}$ & $\begin{array}{c}60.1 \\
(10.1)\end{array}$ & $\begin{array}{l}68.8 \\
(5.8)\end{array}$ & $\begin{array}{l}68.1 \\
(6.4)\end{array}$ & \multirow[t]{2}{*}{0.530} & \multirow[t]{2}{*}{0.001} \\
\hline$p$-value* & $p^{3}$ & 0.001 & $p^{4}$ & 0.210 & & \\
\hline Social & $\begin{array}{c}72.8 \\
(10.8)\end{array}$ & $\begin{array}{l}73.3 \\
(9.2)\end{array}$ & $\begin{array}{l}73.3 \\
(9.2)\end{array}$ & $\begin{array}{c}61.1 \\
(11.8)\end{array}$ & \multirow[t]{2}{*}{0.810} & \multirow[t]{2}{*}{0.001} \\
\hline$p$-value* & $p^{3}$ & 0.999 & $p^{4}$ & 0.001 & & \\
\hline Environment & $\begin{array}{l}70.6 \\
(8.7)\end{array}$ & $\begin{array}{c}61.2 \\
(10.3)\end{array}$ & $\begin{array}{l}71.5 \\
(7.3)\end{array}$ & $\begin{array}{l}71.4 \\
(7.6)\end{array}$ & \multirow[t]{2}{*}{0.550} & \multirow[t]{2}{*}{0.001} \\
\hline$p$-value* & $p^{3}$ & 0.001 & $p^{4}$ & 0.860 & & \\
\hline
\end{tabular}

* Tukey test: $p>0.05, p 1=$ HG vs NG at T1; $22=$ HG vs NG at T2, p3 = T1 vs T2 in the HG group; $\mathrm{p} 4=\mathrm{T} 1$ vs $\mathrm{T} 2$ in the NG group

From $\mathrm{T} 1$ to $\mathrm{T} 2$, the scores of women from the HG group declined in the physical, psychological and environmental domains, but remained constant 
in the social domain. On the other hand, the NG group showed no significant differences in physical, psychological and environmental domains from T1 to $T 2$, but exhibited a decrease in the social relationship domain (Table 3, Figure 1).

Figure 1: Quality of life on pregnant women in all the evaluated domains.
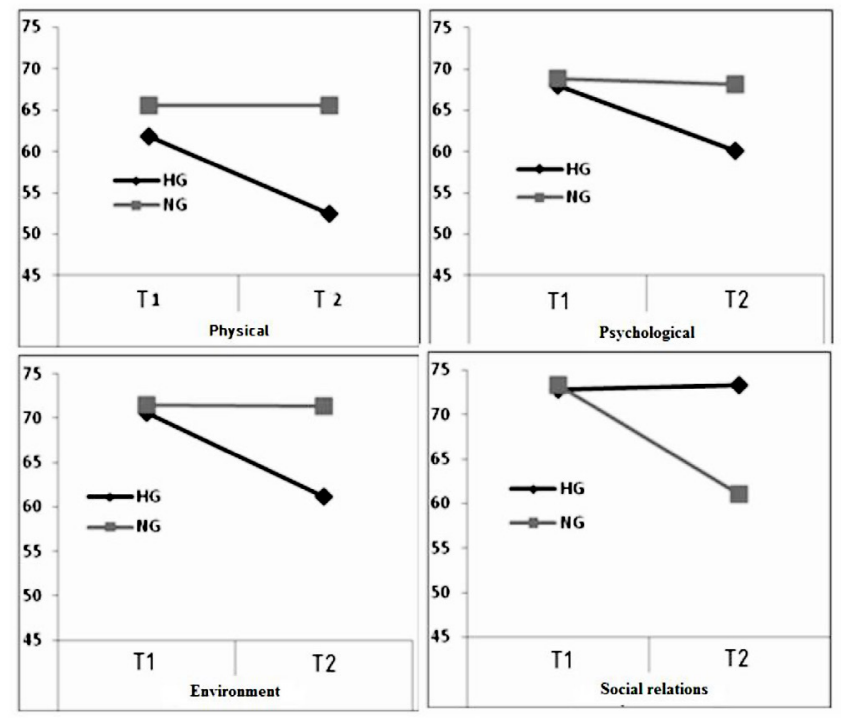

\section{Discussion}

The hyperglycemic (HG) and normoglycemic (NG) groups evaluated in the current study showed different perceptions of QOL, particularly in late pregnancy (T2) and throughout the pregnancy (T1 vs. T2). Regardless of glycemic status, most pregnant women reported having a good QOL at initial assessment, but not at late pregnancy. At T2, most women from the $\mathrm{HG}$ group considered their QOL poor, whereas those from the NG reported it as neither poor nor good; therefore, both hyperglycemic disorder and pregnancy itself are likely to affect their QOL.

Similar results on QOL loss were reported in a study on maternal disease and other complications during pregnancy [19]. It was not found any specific studies that applied WHOQOL-BREF to assess QOL in pregnancies complicated by diabetes or hyperglyce- mia, thereby hindering comparisons. Nevertheless, a recent study of DAWN (Diabetes Attitudes, Wishes and Needs), which applied a specific questionnaire to evaluate aspects related to QOL and wellbeing in pregnant women with GDM, found that the disease diagnosis causes maternal anxiety due to concerns over the risk of malformation and fear that their child will contract diabetes at delivery [20]. The authors suggested that the insecurity caused by the disease increases the frequency of women reporting a decline in QOL throughout pregnancy. In the present study, although most women from both HG and NG groups were satisfied with their health status at T1, the frequency of satisfied women was lower in the HG (56.0\%) than in the NG group (79.4\%). Moreover, in the final evaluation, the prevalence of dissatisfaction with health was higher in the HG group (31.8\%), as opposed to NG women, whose dissatisfaction remained constant at $10.3 \%$ throughout the entire pregnancy. This result can be explained by the altered QOL of individuals with chronic prepregnancy DM, which lowers their satisfaction with health [21]. In the case of GDM, the diagnosis made during pregnancy; and on the treatment conditions that were likely to have a negative effect on the perception of maternal health status, thereby threatening child health.

The physical domain of the WHOQOL -BREF consists of questions related to energy and fatigue; work ability; presence of physical pain; addiction treatment; sleep and rest. The psychological domain involves feelings of acceptance; satisfaction; concentration; meaning of life; and psychological disorders. The environment relates to issues of wellness; leisure; safety; access to health services; and socioeconomic conditions [14]. These aspects are likely compromised in pregnancies complicated by diabetes or hyperglycemia; in other words, affected the results of the current study. Over the course of their pregnancy, women from the HG group exhibited a significant decrease in the physical, psychological and environmental domains of the WHOQOL-BREF 
instrument. However, their scores in the domain of social relationships were not affected throughout pregnancy, being higher than those obtained by the NG group.

Diabetes has been associated with anxiety and depression [22-24]. However, studies on this issue are scarce and conflicting with respect to gestational diabetes. Earlier investigations found that pregnant women with GDM and non-diabetic women exhibit a similar psychological profile $[25,26]$, whereas more recent research shows differences between the psychological profile of diabetic and non-diabetic women; in addition to women with type 1 DM and GDM [27-29].

The social domain involves personal relationships, sexual activity and social support [14]. A qualitative study using semi-structured interviews showed that diabetic women demonstrated lower sexual interest and experienced deterioration in personal relationships [30], which could jeopardize the social domain. These results were not confirmed in our study, which obtained similar scores in women from the HG and NG group at T1; better social relationships in $\mathrm{HG}$ compared to NG at T2; and no change from $\mathrm{T} 1$ to $\mathrm{T} 2$ in the HG. On the other hand, social domain scores decreased over pregnancy in the NG group. Nevertheless, the characteristics of pregnant women regarding marital status, education and work outside from home were similar between HG and NG groups, suggesting that the women were generally provided with social support, a key parameter in the assessment of this domain.

In the current study, the WHOQOL-BREF outcomes showed that pregnant women with diabetes or hyperglycemia lost important determinants of QOL throughout their gestation. Most HG women declared poor QOL and showed unsatisfactory perception of their health status. Evaluation of the WHOQOL-BREF domains indicated a progressive decline in the scores related to physical, psychological and environmental conditions, contrasting with the progressive increase in scores related to the social field.
These results are novel and underscore the need for holistic approaches to the study of hyperglycemia during pregnancy. In addition, this may help improve the quality of management protocols adopted in these high-risk pregnancies.

\section{Acknowledgements}

The authors would thank to the Coordination for the Improvement of Higher Education Personnel (CAPES) to scholarship granted for the first, fourth, fifth and seventh author.

\section{Competing interest}

The authors have declared that no competing interests exist.

\section{References}

1. World Health Organization (WHO). Adherence to long - term therapies: evidence for action. Geneva: WHO, 2003. 191p.

2. Gross JL, Ferreira SRG, Franco LJ, Schimidt MI, Motta DG, $E Q$, et al. Diagnóstico e Classificação do Diabetes Melito e Tratamento do Diabetes Melito Tipo 2. Recomendações da Sociedade Brasileira de Diabetes. Arq Bras Endocrinol Metab. 2000; 44(1):8-35.

3. American Diabetes Association. Gestational Diabetes Mellitus: position statements. Diabetes Care. 2012, 35:S71-51.

4. Rudge MVC, Calderon IMP, Ramos MD, Brasil MAM, Rugolo LMSS, Bossolan G, et al. Hiperglicemia materna diária diagnosticada pelo perfil glicêmico: um problema de saúde pública materno e perinatal. Revista Brasileira de Ginecologia e Obstetrícia. 2005; 27:691-7.

5. Barnes-Powell LL. Infants of diabetic mothers: the effects of hyperglycemia on the fetus and neonate. Neonatal Netw. 2007; 26(5):283-90.

6. Macintosh MC, Fleming KM, Bailey JA, Doyle P, Modder J, Acolet $D$, et al. Perinatal mortality and congenital anomalies in babies of women with type 1 or type 2 diabetes in England, Wales, and Northern Ireland: population based study. BMJ. 2006 22; 333(7560):177

7. HAPO. Study Cooperative Research Group. Hyperglycemia and Adverse Pregnancy Outcomes. N Engl J Med 2008; 358:19912002.

8. Metzger BE, Gabbe SG, Persson B, Buchanan TA, Catalano PA, Damm $P$, et al. International association of diabetes and pregnancy study groups recommendations on the diagnosis and classification of hyperglycemia in pregnancy. Diabetes Care. 2010; 33(3):676-82 
9. Metzger $B E$, Lowe $L P$, Dyer $A R$, Trimble $E R$, Chaovarindr $U$, Coustan DR, et al. Hyperglycemia and adverse pregnancy outcomes. N Engl J Med. 2008 8; 358(19):1991-2002.

10. Cavassini A, Lima S, Calderon I, Rudge M. Avaliações econômicas em saúde: apuração de custos no atendimento de gestações complicadas pelo Diabete. Revista de Administração em Saúde. 2010; $12: 46-30$

11. The Whoqol Group. Development of the World Health Organization WHOQOL-bref. Quality of Life Assesment 1998. Psychol Med 1998; 28:551-8.

12. The Whoqol Group. The World Health Organization quality of life assesment (WHOQOL): development and general psychometric properties. Soc Sci Med 1998; 46:1569-85.

13. Zubaran C, Foresti K, Schumacher MV, Muller LC, Amoretti AL. An assessment of maternal quality of life in the postpartum period in southern Brazil: a comparison of two questionnaires. Clinics. 2009; 64(8):751-6.

14. MP Fleck, S Louzada, M Xavier, E Chachamovich, G Vieira, L Santos, V Pinzon. Application of the Portuguese version of the abbreviated instrument of quality of life WHOQOL-BREF. Rev de Saude Publ. 2000; 34(2):178-183. doi:10.1590/S003489102000000200012

15. Brito DMSD, Araújo TL,d Galvão MTG, Moreira TMM, Lopes MVdO. Qualidade de vida e percepção da doença entre portadores de hipertensão arterial. Cadernos de Saúde Pública. 2008; 24:933-40

16. Lunardi LL, Costa AL, Guerreiro CA, Souza EA. Quality of life in pregnant women with epilepsy versus women with epilepsy. Arq Neuropsiquiatr. 2011; 69(2B):336-41.

17. Vallim et al.: Water exercises and quality of life during pregnancy. Reproductive Health 2011; 8:14/doi:10.1186/1742-4755-8-14.

18. Silva I, Pais-Ribeiro J, Cardoso H, Ramos H. Qualidade de vida e complicações crónica da diabetes. Aná. Psicológica [online]. 2003, vol.21, n.2, pp. 185-194. ISSN 0870-8231.

19. Taşdemir S, Balci E, Günay $O$. Comparison of life quality of pregnant adolescents with that of pregnant adults in Turkey. Ups J Med Sci. 2010; 115(4):275-81.

20. Lapolla A, Di Cianni JG, Di Benedetto A, Franzetti L, Napoli A, Sciacca L, Torlone E, Tonutt L, Vitacolonna E and Mannino D. Quality of Life, Wishes, and Needs inWomen with Gestational Diabetes: Italian DAWN Pregnancy Study. International Journal of Endocrinology 2012, Article ID 784726, 6 pages; doi:10.1155/2012/784726.

21. Cesaretti IUR, Santos VLCG, Vianna LAC. Qualidade de vida de pessoas colostomizadas com e sem uso de métodos de controle intestinal. Revista Brasileira de Enfermagem. 2010; 63:16-21.

22. Chida, Y., \& Hamer, M. An association of adverse psychosocial factors with diabetes mellitus. A meta-analytic review of longitudinal cohort studies. Diabetologia. 2008; 51, 2168-2178.

23. Bradley, C., \& Speight, J. Patient perception of diabetes and diabetes therapy: Assessing quality of life. Diabetes Metabolism Research and Reviews. 2002; 10, S64-S69.
24. Dalfra MG, Nicolucci $A$, Bisson $T$, Bonsembiante $B$, Lapolla $A$. Quality of life in pregnancy and post-partum: a study in diabetic Qual Life Res. 2012; 21:291-298 DOI 10.1007/s11136-0119940-5.

25. Langer, N., \& Langer, O. Emotional adjustment to diagnosis and intensified treatment of gestational diabetes. Obstetrics and Gynecolog. 1994; 84, 329-334.

26. Spirito, A., Williams, C., Ruggiero, L., Bond, A., MvcGarvey, S. T., \& Coustan, D. Psychological impact of the diagnosis of gestational diabetes. Obstetrics and Gynecology. 1989 73(4),562-566.

27. Langer, N., \& Langer, O. Comparison of pregnancy mood profiles in gestational diabetes and preexisting diabetes. The Diabetes Educator. 2000; 26, 667-672.

28. Kim, C., Brawarsky, P., Jackson, R. A., Fuentes-Affick, E., \& Haas, J. S. Changes in health status experienced by women with gestational diabetes and pregnancy-induced hypertensive disorders. Journal of Womens Health. 2005; 14, 729-736.

29. Halkoaho, A., Kavilo, M., Pietila, A.-M., Huopio, H., Sintonen, H., \& Heinonen, S. Does gestational diabetes affect women's health-related quality of life after delivery? European Journal of Obstetrics Gynecology Reproductive Biology. 2010; 148, 4043.

30. Silva L, Santos R, Parada C. Compreendendo o significado da gestação para grávidas diabéticas. Revista Latino-americana de Enfermagem. 2004; 12(6):899-904.

\section{Publish in International Archives of Medicine}

International Archives of Medicine is an open access journal publishing articles encompassing all aspects of medical science and clinical practice. IAM is considered a megajournal with independent sections on all areas of medicine. IAM is a really international journal with authors and board members from all around the world. The journal is widely indexed and classified Q2 in category Medicine. 